\title{
CANTEIRO DE OBRA, CANTEIRO DE SUBJETIVIDADE: UMA ANÁLISE PSICODINÂMICA DO TRABALHO DE TÉCNICOS DE SEGURANÇA DO TRABALHO
}

\section{ARTIGO ORIGINAL}

FARIA, Gabriela Iduino da Paixão Terra de ${ }^{1}$

FERREIRA, João Batista ${ }^{2}$

FARIA, Gabriela Iduino da Paixão Terra de. FERREIRA, João Batista. Canteiro de obra, canteiro de subjetividade: Uma análise psicodinâmica do trabalho de técnicos de segurança do trabalho. Revista Científica Multidisciplinar Núcleo do Conhecimento. Ano 05, Ed. 04, Vol. 06, pp. 61-90. Abril de 2020. ISSN: 2448-0959, Link de acesso: https://www.nucleodoconhecimento.com.br/psicologia/canteiro-deobra

\section{RESUMO}

O presente trabalho tem por objetivo realizar uma análise psicodinâmica do trabalho dos técnicos de segurança do trabalho em obras da construção civil. O referencial teórico utilizado nesta pesquisa foi a psicodinâmica do trabalho, em conjunto com bibliografias atuais sobre o tema saúde e segurança. Além da revisão bibliográfica, foram realizadas seis entrevistas com técnicos de segurança do trabalho, analisadas segundo o método da Análise do Núcleo de Sentidos. Viu-se que o trabalho na contemporaneidade é permeado por estratégias onde a razão econômica e a razão financeira tendem a se sobrepor aos cuidados com a saúde dos trabalhadores. Neste

\footnotetext{
${ }^{1}$ MBA em Gestão de Pessoas, Pós-graduação em Gestão Pública, Graduação em Psicologia.

2 Pós-doutorado em Filosofia na Université Paris 1 Panthéon-Sorbonne. Doutor em Psicologia Social e do Trabalho (UnB). Mestre em Psicologia (UnB). Psicólogo (UFRGS).
} 
contexto, a vida fica em segundo plano, uma vez que a produção é priorizada em detrimento daquela. Os acidentes foram relacionados às condições proporcionadas pela organização do trabalho, mas esta associação tende a ser negada ou minimizada por meio do processo de culpabilização dos trabalhadores, o que configura um grande desafio para os técnicos de segurança do trabalho. Na realidade da obra, onde a regra geral é a de que a produção não pode parar, os próprios técnicos de segurança do trabalho acabam capturados por esta lógica, ao acreditarem que a segurança dos trabalhadores deve ser assegurada pela própria conduta de cada um destes. São trazidas vivências de sofrimento no que concerne a interação com outros trabalhadores, embora as vivências de prazer no trabalho estejam ligadas ao bemestar que experienciam ao sentirem que ajudam a preservar a vida de outros trabalhadores e ao reconhecimento do seu trabalho pelos outros trabalhadores.

Palavras-chave: Psicologia, Psicodinâmica do Trabalho, Segurança do Trabalho.

\section{INTRODUÇÃO}

Com a realização da Copa do Mundo de 2014 no Brasil e as Olimpíadas de 2016 na cidade do Rio de Janeiro, o setor de construção civil nacional vive uma fase de intensa expansão. Com a carência das cidades no que se refere a infraestrutura exigida para receber eventos deste porte, a necessidade de construção e reforma de estádios, metros, aeroportos e outras obras de construção pesada gerou diversas demandas.

Devido às expectativas existentes em torno destes dois eventos, as construtoras não apenas estão em franco crescimento, como também ganharam maior visibilidade. Com os holofotes voltados para si, todos os aspectos que envolvem as obras têm repercutido intensamente na mídia. Esta exposição permitiu que o conhecimento dos acidentes graves e fatais neste tipo de trabalho alcançasse pessoas que não vivem diretamente a realidade da obra, dentre elas eu. Considerando apenas os acidentes fatais, foram perdidas 9 vidas nas obras nos estádios da Copa.

Embora a mídia tenha noticiado estas fatalidades, a verdadeira dimensão da questão não foi esclarecida. Segundo o Anuário Estatístico de Acidentes do Trabalho 
disponibilizado pela Previdência Social, em 2012 foram registrados 705.239 acidentes no Brasil (dado mais recente divulgado até o momento). Além disso, esta exposição por si não conduziu a um amplo espaço de investigação e reflexão profundas acerca do contexto produtor destes acidentes e de como os trabalhadores estão inseridos nele.

Este trabalho propõe-se, portanto, a pensar este contexto, atravessado pelas lógicas produtivista e financeira, e suas implicações na concepção hegemônica de saúde e segurança do trabalho. Esta lógica traz como essência o discurso da culpabilização do trabalhador, desconsiderando as implicações da organização do trabalho nos acidentes. Assim, o objetivo geral deste trabalho é realizar uma análise psicodinâmica do trabalho dos técnicos de segurança do trabalho em obras da construção civil. Os objetivos específicos são: o trabalho real e o trabalho prescrito; vivências de sofrimento e prazer no trabalho; estratégias defensivas; e sentido do trabalho.

Esta pesquisa utiliza como método a revisão bibliográfica sobre assunto e a realização de entrevistas semiestruturadas com técnicos de segurança do trabalho que trabalham em obras da construção civil. A abordagem utilizada é a psicodinâmica do trabalho, que se propõe a investigar as relações entre trabalho e saúde, quando este contexto é gerador de saúde ou adoecimento e qual o sentido do trabalho para estes trabalhadores.

Para analisar os dados, foi utilizada a metodologia de Análise de Núcleo de Sentidos, proposta por Mendes (2007), onde será investigado o contexto de trabalho destes técnicos, as vivências de prazer e sofrimento criativo, além dos efeitos deste trabalho na saúde destes trabalhadores.

O capítulo 1 apresenta brevemente como está configurada a organização do trabalho na contemporaneidade. Buscou-se entender as origens deste atual modelo e apontar algumas de suas características, como o incremento do individualismo, a negação do próprio sofrimento e a ausência de empatia. O espaço de trabalho torna-se, então, um lugar onde não se fala, não se vê e não se ouve. No limite, pode levar à perda de identidade e de sentido do trabalho. 
O capítulo 2 traz a história da Saúde e Segurança do Trabalho, desde os primeiros registros de que se tem notícia, passando pelos principais marcos e pela fundação das principais instituições que estão atreladas ao tema. Ainda assim, mesmo com todas as pesquisas já realizadas, e a despeito de todo os avanços tecnológicos de dispositivos de proteção, o número de acidentes no Brasil e no mundo ainda é alarmante.

O capítulo 3 caracteriza a profissão do técnico de segurança do trabalho. É apresentada a sua definição segundo a Classificação Brasileira de Ocupações e sua disposição na lei. Também caracteriza o SESMT - Serviços Especializados em Engenharia de Segurança e Medicina do Trabalho, explicando o seu dimensionamento e concluindo quanto da importância do técnico de segurança do trabalho.

O capítulo 4 apresenta a abordagem da psicodinâmica do trabalho, inaugurada por Dejours na década de 80 , que tem como objeto de estudo a relação entre a organização do trabalho e as vivências de prazer e sofrimento de quem trabalha. São trazidos os principais conceitos desta abordagem, dentre eles Trabalho Prescrito e Trabalho Real, Sofrimento Criativo e Sofrimento Patogênico, Mobilização Subjetiva, Sentido do Trabalho e Estratégias Defensivas. Também são colocadas algumas considerações sobre a pesquisa nesta abordagem.

O capítulo 5 expõe o método da presente pesquisa. A análise dos dados se deu pela Análise de Núcleos de Sentido (MENDES, 2007).

No capítulo 6 está a análise das entrevistas e discussão dos resultados. Os núcleos de sentido identificados foram: "Como eles tão sempre com o prazo apertado, eles tão sempre muito corridos, eles acabam não respeitando.", que diz respeito às diferenças encontradas no trabalho real em relação ao trabalho prescrito; "Não é um trabalho fácil, porque lidar com gente é um pouco puxado, um pouco difícil.", que retrata as vivências de sofrimento no trabalho; "E eu cooperei pra isso, é muito bom.", que indica as vivências de prazer no trabalho; "Esses são os pontos negativos. Mas os positivos também acabam fazendo valer.", que expressa as estratégias defensivas empregadas 
por estes trabalhadores; e "O trabalho aqui repercute na vida pessoal da gente.", que busca compreender o sentido atribuído ao ate de trabalhar em sua atividade profissional.

\section{TRABALHO NA CONTEMPORANEIDADE}

A organização do trabalho sofreu diversas reconfigurações desde o início da civilização humana até os tempos atuais. A Revolução Industrial é considerada o grande marco que desencadeou a atual configuração, o capitalismo.

Ao contrário do que sugere a maioria dos historiadores, o nascimento das fábricas num primeiro momento se deu pela necessidade de controlar a produção dos artesãos, e não pelo avanço tecnológico das máquinas da época (DECCA, 1995).

Segundo Decca, o sistema de fábrica surgiu, não como resultado do desenvolvimento tecnológico da época, mas da necessidade que o empresário capitalista, papel que surgiu a partir da figura do negociante que intermediava a produção artesanal e o mercado, teve de controlar a produção, tanto para evitar sabotagens, quanto para tornar a produção mais eficiente. Para se obter uma maior rentabilidade, seria necessário regular a forma como os artesãos trabalhavam, o que seria possível através de um regime de disciplina e controle.

No início, essa nova maneira de organização não foi aceita de forma passiva pelos artesãos, que não estavam acostumados à disciplina, uma vez que este novo regime significava abrir mão da liberdade que eles tinham até então. Como eram detentores do saber técnico, sentiram-se seguros para ir de encontro a esta nascente administração das empresas fabris, muitos deles destruindo os maquinários das fábricas. No entanto, alguns anos mais tarde esse quadro virou. Com os avanços tecnológicos, as máquinas podiam agora produzir muito mais utilizando menos trabalhadores. Logo, aqueles menos submissos às novas regras de disciplina seriam os primeiros dispensados, o que tornou a mão-de-obra mais passiva diante do novo quadro. O poder saiu dos trabalhadores e passou para o dono das máquinas, uma vez que essa situação se tornou uma ferramenta de controle social, pois os não 
adaptados perderiam o sustento. Expropriados dos meios de produção e do saber técnico pelo desenvolvimento do novo aparato tecnológico, o indivíduo viu-se submetido às exigências de quem os detinha (DECCA, 1995).

Neste novo contexto, a Revolução Industrial trouxe consigo não apenas novidades tecnológicas, mas também a formação de mecanismos que gerariam a concentração de saber, a organização da força de trabalho, o poder e o controle social. Na busca por manter-se e garantir a continua acumulação de capital, a fábrica começou a se fazer valer de estratégias relacionadas a produtividade e ganhos financeiros (DECCA, 1995).

Desde a Revolução Industrial até a configuração atual do trabalho, estas estratégias que colocaram a razão econômica e financeira atropelando a razão ética e política geraram duras consequências. Segundo Ferreira (2009), o incremento do individualismo, da negação do próprio sofrimento e da ausência de empatia, tornando os indivíduos alheios também ao sofrimento do outro são resultados de lógicas como "[...] os fins justificam os meios; ações de curto prazo; a constituição da identidade via capacidade de consumo; a banalização da injustiça social" (FERREIRA, 2009, p.19).

O incremento do individualismo, que é tido pelos trabalhadores como a única forma de sobreviver a este sistema econômico, age como uma defesa onde não se fala, não se vê e não se ouve. Dessa forma, desestrutura-se a solidariedade, e sozinho não há possibilidade de mobilização subjetiva. Cala-se o próprio sofrimento e ignora-se o sofrimento alheio, o que pode levar à perda de identidade e do sentido do trabalho. $\mathrm{A}$ longo prazo, esta estratégia defensiva pode ainda ao se esgotar, transformar-se em patologia (DEJOURS, 1999; FERREIRA, 2009).

Dejours traz ainda que, é justamente esta conduta humana que mantém a máquina funcionando. O sofrimento no trabalho, o medo de perder o emprego, e consequentemente o medo da exclusão, incrementa o individualismo, que por sua vez desencadeia estratégias defensivas que camuflam o seu sofrimento. Estas estratégias defensivas, repletas de engenhosidade, abafam a percepção do sofrimento alheio, não permitindo a mobilização subjetiva. Com a banalização da injustiça social, 
consentimos e nos submetemos a estas regras. Insensíveis ao sofrimento, não há reflexão, nem mobilização contra esta lógica, mas toleramos o mal que nos é feito e permitimos que se perpetue (DEJOURS, 1999).

Transformar esta realidade só será possível quando os próprios trabalhadores tomarem consciência de seu sofrimento, e, por meio do coletivo, enfrentarem o atual discurso, que não deve ser tomado como verdade absoluta.

\section{SAÚDE E SEGURANÇA DO TRABALHO}

Os primeiros registros que apontam para o que hoje é denominado como segurança do trabalho são datados do Egito Antigo. A expressão em si surgiu de debates sobre segurança, saúde e bem-estar, que precederam a fundação da Organização Internacional do Trabalho (OIT), como parte do Tratado de Versalhes, em 1919, após a Primeira Guerra Mundial. Segundo Antloga (2013, p.369), segurança do trabalho é o "[...] conjunto de leis, políticas, normas e formas de gestão que visam garantir a segurança física, cognitiva e afetiva do trabalhador, reduzindo seu custo humano no trabalho e promovendo a cidadania nos contextos laborais.".

Do Egito Antigo até o fim da Primeira Guerra Mundial, o tema da segurança do trabalho surgiu em outras circunstâncias. Na Roma Antiga, preocupados com a inalação de poeira metálica, Plínio e Rotário recomendaram o uso de máscaras para os trabalhadores de fábricas de armas. Na Idade Média, houve a preocupação por parte dos fabricantes com a higiene dos trabalhadores, como meio de prevenção de doenças, inclusive as profissionais que naquela época já haviam sido identificadas (ANTLOGA, 2013).

Foi no Renascimento que estas preocupações passaram a ser sistematizadas. As informações acerca de saúde do trabalhador e medicina do trabalho começaram a ser organizadas, e também surgiram, pela primeira vez, estudos a respeito da inspeção médica no trabalho, além de um trabalho sobre causas e prevenção de acidentes de trabalho registrado nos anais de Academia de Medicina da França (ANTLOGA, 2013). 
A partir de então, a preocupação com a segurança e a saúde do trabalhador começa a se difundir, principalmente com a Revolução Industrial, quando acidentes e problemas com a saúde ganham grandes proporções devido às novas condições de trabalho e à necessidade de manuseio de máquinas na atividade laboral, sem que houvesse preparo ou qualquer equipamento de proteção a segurança (ANTLOGA, 2013; MENDES e DIAS, 1991).

Foi nesta época que surgiu a medicina do trabalho, disciplina que se propunha a atuar dentro do ambiente de trabalho de forma a identificar e tratar aspectos que causassem danos à saúde do trabalhador, com a intenção de controlar e manter a força de trabalho produtiva. A medicina do trabalho era centrada na figura do médico, que tinha autoridade na proteção da saúde e era responsabilizado por quaisquer ocorrências relacionadas à saúde dos operários (MENDES e DIAS, 1991).

Há indícios de que entre a segunda metade do século XIX e o início do século XX, surgiu concomitantemente nos Estados Unidos e na Inglaterra os primeiros procedimentos para prevenção de acidentes no trabalho, até que a OIT fosse fundada com a missão de elaborar e implementar normas internacionais do trabalho, além de promover pesquisas e debates sobre o tema ao redor do mundo. No mesmo ano da criação da OIT, é promulgada no Brasil a primeira lei sobre acidentes de trabalho, que regulava as obrigações resultantes dos acidentes no trabalho, sem, no entanto, garantir que houvesse melhoria nas condições de trabalho (ANTLOGA, 2013).

Posteriormente, a OIT também demonstrou preocupação em garantir serviços médicos aos trabalhadores, através da Recomendação 97, intitulada "Proteção da Saúde dos Trabalhadores", que em 1953 orientava que os Estados Membros da OIT "[...] fomentassem a formação de médicos do trabalho qualificados e o estudo da organização de 'Serviços de Medicina do Trabalho'” (MENDES e DIAS, 1991, p.2). Os anos subsequentes foram de intensa atuação da OIT nos assuntos relacionados ao tema, culminando, em 1959, na Recomendação 112, sobre "Serviços de Medicina do Trabalho", primeiro documento de parâmetro internacional (MENDES e DIAS, 1991). 
Este documento instituía o "Serviço de Medicina do Trabalho" como um serviço que deveria ser disponibilizado no próprio local de trabalho ou imediações, com a finalidade de proteger os trabalhadores de riscos à saúde e favorecer a adaptação física e mental dos trabalhadores às suas condições de trabalho. Estes propósitos da medicina tinham o caráter de buscar alcançar o limite da produtividade.

Foi em 1943, com a Promulgação da Consolidação das Leis do Trabalho (CLT), que a Segurança do Trabalho passou a ser uma área específica, além de pela primeira vez haver a proteção legal do trabalhador, como garantias a respeito da remuneração, incluindo, por exemplo, os adicionais de periculosidade e insalubridade. A CLT, no entanto, além de excluir os servidores públicos e trabalhadores informais, também não contemplava questões da ordem da segurança psicológica e cognitiva (ANTLOGA, 2013). E, mesmo com a promulgação da CLT, a segurança do trabalho foi vista até a década de 70 como despesas adicionais pelas empresas, que atuava com foco nos acidentes já ocorridos, e não com uma visão preventiva.

Este quadro começou a mudar com a criação da Fundação Jorge Duprat Figueiredo de Segurança e Medicina do Trabalho, a FUNDACENTRO. Esta instituição traz como missão:

Produção e difusão de conhecimentos que contribuam para a promoção da segurança e saúde dos trabalhadores e das trabalhadoras, visando ao desenvolvimento sustentável, com crescimento econômico, eqüidade social e proteção do meio ambiente (FUNDACENTRO, 20-).

A FUNDACENTRO foi um marco no Brasil da evolução da medicina do trabalho para a saúde ocupacional. A medicina do trabalho, centralizada na figura do médico e que focava na proteção do empregado contra os riscos e na busca da sua adaptação as condições de trabalho, passou a não mais dar conta da demanda. A tecnologia industrial desenvolveu de forma acelerada os processos industriais, e a medicina do trabalho não dava conta dos adoecimentos decorrentes dos processos de produção. A saúde ocupacional surgiu então com a disciplina que iria controlar os riscos 
ambientais, dispondo-se de uma equipe multidisciplinar que iria atuar não mais sobre o trabalhador, mas sobre o ambiente.

Foi da FUNDACENTRO de onde saiu os insumos para, em 1978, as Normas Regulamentadoras (NRs) serem promulgadas pela extinta Secretaria de Segurança e Medicina do Ministério do Trabalho. É só então que as questões referentes a saúde e segurança dos trabalhadores brasileiros passam a ter amparo legal. Estas normas se aplicam a todos os empregos regulamentados pela CLT, além de abranger empresas públicas e órgãos públicos da administração direta e indireta (ANTLOGA, 2013).

É importante destacar também que, em 1970, é fundada nos Estados Unidos o National Institute for Occupational Safety and Health (NIOSH), agência federal responsável por realizar estudos e elaborar recomendações que previnam doenças e lesões provenientes do trabalho. Este instituto definiu questões que até então estavam vagas na CLT, como, por exemplo, a regulamentação dos limites de carga transportada por humanos (ANTLOGA, 2013).

Outro ponto de atenção é que, mesmo após a promulgação das NRs, ainda não havia no Brasil documentos que tratassem com atenção no âmbito da segurança psicológica e cognitiva do trabalhador (ANTLOGA, 2013).

Pensando na década em que estamos, estudos tem revelado que, mesmo com o desenvolvimento tecnológico e de todos os equipamentos e mecanismos de segurança para proteger o trabalhador, o número de acidentes do trabalho no Brasil e no mundo ainda é alarmante. Tem-se concluído que, as mudanças que buscam aprimorar a saúde e a segurança do trabalhador devem extrapolar as questões de equipamentos e normas de prevenção e começar a atingir também a gestão organizacional. Para se garantir efetivamente a proteção dos trabalhadores, é preciso começar a refletir também acerca das questões que envolvem a gestão organizacional, como metas, prazos e resultados (ANTLOGA, 2013; MENDES e WÜNSCH, 2007). 


\section{A PROFISSÃO TÉCNICO DE SEGURANÇA DO TRABALHO}

A profissão de técnico de segurança do trabalho é regulamentada pela Lei $\mathrm{N}^{0} 7.410$, de 27 de novembro de 1985.

Segundo a Classificação Brasileira de Ocupações, os Técnicos de Segurança do Trabalho:

Elaboram, participam da elaboração e implementam política de saúde e segurança no trabalho (sst); realizam auditoria, acompanhamento e avaliação na área; identificam variáveis de controle de doenças, acidentes, qualidade de vida e meio ambiente. Desenvolvem ações educativas na área de saúde e segurança no trabalho; participam de perícias e fiscalizações e integram processos de negociação. Participam da adoção de tecnologias e processos de trabalho; gerenciam documentação de sst; investigam, analisam acidentes e recomendam medidas de prevenção e controle (BRASIL, 2002).

O técnico de segurança deve estar presente em todas as empresas, compondo a equipe de saúde ocupacional. Segundo o artigo 162 da Consolidação das Leis do Trabalho (CLT):

As empresas, de acordo com normas a serem expedidas pelo Ministério do Trabalho, estarão obrigadas a manter serviços especializados em segurança e em medicina do trabalho. (Redação dada pela Lei no 6.514 , de 22.12.1977) (BRASIL, 1977).

Este artigo trata do SESMT - Serviços Especializados em Engenharia de Segurança e Medicina do Trabalho. Outros profissionais que podem compor a equipe do SESMT são o médico do trabalho, o engenheiro de segurança do trabalho, o enfermeiro do trabalho e o auxiliar de enfermagem.

O SESMT é regulamentado pela Norma Regulamentadora 4 (NR4), que estabelece as principais atribuições destes profissionais, além do dimensionamento da equipe em 
função do grau de risco da principal atividade da empresa versus o número de empregados total.

Segundo texto da NR4 (BRASIL, 1983), o menor dimensionamento do SESMT, ou seja, quando ele é composto por apenas um profissional, este deve ser o técnico de segurança do trabalho. Observa-se, então, que qualquer formação de equipe do SESMT sempre será composta de pelo menos um técnico de segurança do trabalho.

\section{PSICODINÂMICA DO TRABALHO}

$\mathrm{Na}$ década de 80 , a partir de estudos sobre medicina do trabalho, ergonomia, psiquiatria, psicopatologia e psicanálise, o francês Christophe Dejours inaugurou a Psicodinâmica do Trabalho, disciplina que se propõe a investigar a inter-relação entre trabalho e saúde. O objeto de estudo desta abordagem é a relação entre a organização do trabalho e as vivências de prazer e sofrimento de quem trabalha, e quando estas vivências podem resultar em saúde, adoecimento ou patologias (DEJOURS, 2011).

Dois conceitos centrais da psicodinâmica do trabalho são o Trabalho Prescrito e o Trabalho Real.

O primeiro diz respeito às condições e relações do trabalho que são impostas aos trabalhadores. Essas condições podem ser formais, como por exemplo, descritas em manuais ou procedimentos, ou podem ser informais, como determinadas em reuniões ou orientadas verbalmente (COSTA, 2013).

Porém, por mais que se tente prever as situações e planejar as tarefas, o trabalho prescrito será sempre permeado pelo inesperado, pelas situações imprevistas. E o inesperado do trabalho sempre irá exigir respostas que estão para além do prescrito. Essa parte da realidade que se revela ao sujeito por sua resistência ao prescrito é denominada Real do Trabalho (COSTA, 2013). 
A diferença entre os o Trabalho Prescrito e o Trabalho Real é considerado o próprio trabalho ou a forma de trabalhar do trabalhador, forma esta que deverá ser inventada ou descoberta a cada situação pelo sujeito que trabalha (COSTA, 2013).

Invariavelmente, ao se deparar com os incidentes e imprevistos do real, o trabalhador vivencia a experiência do fracasso. $O$ fracasso causa sofrimento, e na busca por aliviar este sofrimento, este pode encaminhar-se para dois diferentes destinos: o sofrimento criativo ou o sofrimento patogênico. De acordo com Mendes e Muller (2013), o trabalho pode ser fonte de prazer e também fonte de sofrimento, onde tanto o prazer quanto 0 sofrimento são resultados de um arranjo entre a história do indivíduo e a organização do trabalho.

Quando o sofrimento mobiliza o sujeito, e este busca transformá-lo em algo benéfico para si, pode ser chamado de sofrimento criativo. Este sofrimento é capaz de mobilizar os recursos internos do trabalhador, num processo de engajamento marcado pela inteligência prática, pela cooperação, pelo reconhecimento e pelo espaço para discussão. A inteligência prática auxilia a resistir ao prescrito a partir de uma racionalidade subjetiva particular, enquanto a cooperação fomenta confiança, discussão e construção de regras de trabalho para gerir a organização do trabalho. Essas duas dimensões são condições para o coletivo de trabalho existir (MORAES, 2013; MENDES e DUARTE, 2013).

Através da cooperação, da integração e articulação das diferenças, o trabalho conquista visibilidade. É levado ao espaço público e assim pode ser reconhecido pela chefia e por outras equipes, tornando-se um estímulo para mobilização subjetiva "[...] a dinâmica do reconhecimento - que é retribuição moral e simbólica ao esforço e investimento do trabalhador na organização do trabalho [...]" (MENDES e DUARTE, 2013, p.260).

Ao ressignificar o sofrimento imposto pelo trabalho relacionando sua subjetividade com o coletivo e com o saber-fazer, o indivíduo pode dar sentido ao seu trabalho como vivência de prazer. O sentido do trabalho é uma representação do ato de trabalhar, em que há apreciação das situações de trabalho vivenciadas. A sua construção será 
sempre coletiva, embora seja indispensável a participação individual de cada trabalhador. O sentido do trabalho fortalece a identidade do sujeito e traz ganhos no plano da subjetividade (COSTA, 2013).

Dessa forma, o sofrimento no trabalho pode se tornar uma fonte de prazer e saúde através de estratégias de enfrentamento e de mobilização subjetiva.

No entanto, quando o trabalhador não consegue subverter o sofrimento no trabalho em prazer, ele irá utilizar-se de estratégias defensivas para minimizar a percepção do sofrimento. Estas estratégias, que são concebidas de maneira inconsciente tanto pelo individuo como coletivamente, mantém o sujeito no plano da normalidade, permitindo a ele que continue trabalhando. Porém, estas estratégias não alteram a organização do trabalho, e, portanto, as vivencias de fracasso continuam a ser produzidas, o que poderá levar as estratégias defensivas a se esgotarem, agravando o sofrimento e caracterizando-o como sofrimento patogênico (MORAES, 2013).

De acordo com Moraes (2013), as estratégias defensivas mais decorrentes são a negação e a racionalização.

A negação é caracterizada pela presença do individualismo, do isolamento, da desconfiança, e da banalização das dificuldades da organização de trabalho: nega-se que a organização do trabalho seja a causa do sofrimento, e culpa-se

A resistência psíquica inconsciente do sujeito promove anestesia, aceitação ou tolerância com o sofrimento. No limite, esta fragilização do trabalhador abre espaço para a manifestação de patologias no trabalhador.

Segundo Mendes (2007), toda situação de trabalho é particular, funcionando sob uma dinâmica própria. Portanto, não existe certeza de sofrimento ou de prazer no trabalho baseando-se no tipo de trabalho, nas atividades em si ou na hierarquia. Essas vivências variam de acordo com a subjetivação, com a mobilização subjetiva e as estratégias defensivas adotadas pelo sujeito para lidar com a organização do trabalho. Dessa forma, num mesmo contexto prescrito um sujeito pode adoecer, enquanto o 
outro pode, dentro da flexibilidade que existe ali, implicar-se de maneira criativa, obter prazer e fortalecer sua saúde (MENDES, 2007).

Portanto, para entender a situação de trabalho de um determinado ambiente, é preciso estudá-lo em particular, privilegiando a escuta das próprias pessoas que o compõem. É somente desta forma que se torna possível uma análise da realidade vivenciada ali, realidade esta composta por aspectos tanto visíveis quanto invisíveis (MENDES, 2007).

Através da escuta do que as pessoas que experienciam esta situação de trabalho, buscasse identificar, além do real do trabalho, quais são as vivencias de prazer e de sofrimento, de quais formas ocorrem as mobilizações subjetivas e quais são as estratégias de defesa, além de aspectos que evidenciam um sofrimento patogênico, transformando o trabalho em um trabalho morto, uma atividade não faz sentido para a pessoa onde, no limite, e ela vivencia um a insensibilização e alienação (MENDES, 2007).

Ainda para Mendes (2007), a Psicodinâmica do Trabalho não pode ser definida por um método único e universal, como uma fôrma aplicável a qualquer situação de trabalho. Justamente por considerar que as situações e pessoas são singulares, é inerente a impossibilidade de que sua técnica seja desdobrada de forma idêntica para qualquer coletivo. O método, portanto, se faz em um conjunto de técnicas, metodologias e ferramentas que devem funcionar a serviço do objeto em questão de cada pesquisa. É somente quando há uma verdadeira articulação entre técnica e objeto que se torna possível enxergar a realidade da daquele grupo (MENDES, 2007).

Considerando que a escuta do coletivo é essencial nesta metodologia, a entrevista é uma premissa para qualquer pesquisa que se pretenda ter a abordagem da Psicodinâmica. O ponto básico desta técnica, em qualquer situação, é a necessidade da real presença do pesquisador durante a entrevista. Ele deve assumir uma postura clínica, pois é apenas possuindo uma escuta verdadeiramente envolvida que se poderá perceber e se atentar aos elementos que não estão presentes no discurso manifesto. Um estudo que investigue apenas o dito nas entrevistas está fadado a 
equívocos de interpretação e análise da situação real do trabalho, uma vez que o discurso trazido pelos entrevistados está muitas vezes atravessado pelos discursos formatados daquele ambiente, não sendo de fato o que está presente na subjetividade dos trabalhadores daquele grupo (MENDES, 2007).

Traçadas estas considerações, as entrevistas atendem as regras pré-estabelecidas para qualquer entrevista elaborada e conduzida para uma pesquisa científica. Como técnica, utiliza-se este espaço de fala e escuta para recolher dados acerca do objeto de estudo (MENDES, 2007).

Dentro desta abordagem, esta pesquisa traz ainda a pretensão de conseguir mobilizar os pesquisados a realizarem elaborações que possibilitem a transformação de seus sofrimentos que tenham fim em si em sofrimentos criativos (MENDES, 2007).

\section{MÉTODO}

Durante três meses foram realizadas entrevistas semiestruturadas com seis técnicos de segurança do trabalho de duas obras de consórcio da construção civil. A primeira obra relacionada a mobilidade urbana no Rio de Janeiro e a segunda relacionada a construção de uma hidrelétrica na região Norte do Brasil.

Dos seis técnicos entrevistados, três trabalham juntos em uma mesma obra de mobilidade urbana no Rio de Janeiro e três trabalham juntos em uma mesma obra de uma hidrelétrica no norte do Brasil. Apenas um profissional tinha cargo de supervisão. Duas profissionais eram do sexo feminino e ambas trabalham na obra de mobilidade urbana. Todos os demais entrevistados eram homens. Todos os profissionais têm entre 24 e 37 anos. A fim de garantir o anonimato dos entrevistados, todos serão identificados por letras.

As entrevistas tinham como objetivo procurar entender o contexto de trabalho dos técnicos de segurança do trabalho que estavam há pelo menos dois anos na função e que atuavam nestas obras há pelo menos seis meses. Buscou-se compreender 
também suas vivências de prazer e sofrimento, quais as estratégias defensivas e mobilização utilizadas e como o trabalho afeta a vida destes trabalhadores.

Para a análise destes dados, foi utilizado o método da Análise de Núcleos de Sentido (MENDES, 2007). O método consiste em agrupar as falas que emergiram mais fortemente nas entrevistas em núcleos de sentidos e a partir destas unidades pensar o contexto de trabalho específico que a pesquisa se propõe a estudar.

\section{ANÁLISE DAS ENTREVISTAS E DISCUSSÃO DOS RESULTADOS}

\subsection{CARACTERIZAÇÃO DO CONTEXTO DE TRABALHO}

A obra de mobilidade urbana pesquisada situa-se no estado do Rio de Janeiro e é executada por um consórcio, formado por três empresas do setor da construção civil.

A obra da hidrelétrica situa-se no estado do Pará e é executada por um consorcio composto por dez empresas do setor da construção civil.

Todos os profissionais trabalham um turno diário de 8 horas. Os três pesquisados de cada obra trabalham no mesmo turno e respondem para o mesmo superior direto.

Sobre as tarefas realizadas no trabalho, pode-se dividir os técnicos em dois grupos, os que trabalhavam com a gestão da segurança e os que trabalhavam diretamente no campo. Na primeira categoria, os técnicos tinham como atividades realizar as supervisões dos técnicos de segurança do campo, tratar de documentações referentes às subcontratadas, calcular indicadores e manejar os dados de acidentes.

$\mathrm{Na}$ segunda categoria, o trabalho é mais dinâmico, pois os técnicos trabalham diretamente na frente de serviço, fiscalizando, orientando e autorizando a liberação das equipes de produção.

Uma característica bastante presente na categoria dos técnicos de segurança do trabalho é que muitas vezes estes trabalhadores passaram juntos por outras obras, e são os responsáveis por trazerem uns aos outros para outras obras. 
Foram identificados cinco núcleos de sentido:

Núcleo 1: "Como eles tão sempre com o prazo apertado, eles tão sempre muito corridos, eles acabam não respeitando.", que diz respeito às diferenças encontradas no trabalho real em relação ao trabalho prescrito.

Núcleo 2: "Não é um trabalho fácil porque lidar com gente é um pouco puxado, um pouco difícil.", que retrata as vivências de sofrimento no trabalho.

Núcleo 3: "E eu cooperei para isso, é muito bom.", que indica as vivências de prazer no trabalho.

Núcleo 4: "Esses são os pontos negativos. Mas os pontos positivos também acabam fazendo valer.", que expressa as estratégias defensivas empregadas por estes trabalhadores.

Núcleo 5: "O trabalho aqui repercute na vida pessoal da gente.", que busca compreender o sentido atribuído ao ato de trabalhar em sua atividade profissional.

\subsection{NÚCLEO 1: "COMO ELES TÃO SEMPRE COM O PRAZO APERTADO, ELES TÃO SEMPRE MUITO CORRIDOS, ELES ACABAM NÃO RESPEITANDO"}

O núcleo de sentido "Como eles tão sempre com o prazo apertado, eles tão sempre muito corridos, eles acabam não respeitando." diz respeito às diferenças encontradas no trabalho real em relação ao trabalho prescrito.

É possível identificar que a lógica do produtivismo permeia o trabalho dos técnicos que atuam nas duas categorias identificadas anteriormente. No trabalho dos técnicos que atuam na gestão, a demanda diária é sempre excessiva, como traz a fala de B, que trabalha diretamente com documentações de segurança e fechamento de indicadores para cada uma das empresas do consórcio da obra de mobilidade urbana: "Eu costumo dizer que meu horário ele não poderia ser 24 horas. Precisaria de 48 
horas, porque a demanda é muito grande para o pouco tempo de horário de trabalho" (B.).

Nesta mesma obra, a técnica de segurança que faz a gestão do campo também traz as dificuldades relacionadas ao tempo versus demanda: "Nas 25 horas por dia a gente consegue alguma coisa. Nem que seja no horário vindo de meia noite às seis da manhã" (C.).

No trabalho dos técnicos da segunda categoria, a razão econômica e a razão financeira funcionam de tal forma que é inconcebível que a construção paralise por qualquer razão, inclusive por razão de segurança. A segurança do trabalho é vista como a área que atrasa a produção. Segundo o prescrito deste trabalho, é preciso que os técnicos de segurança realizem vistorias e liberem as áreas de trabalho. Como a obra "não pode parar", muitas vezes a segurança é desrespeitada a fim de agilizar o andamento dos serviços. O prescrito do trabalho é sempre atropelado pelo real da produção. Este aspecto pode ser observado no seguinte trecho relatado: "E como todas as outras [obras] ela tem prazo para entregar, as vezes acontece um atropelo, mas faz parte" (F.). Também é possível identificar essa perspectiva nos seguintes trechos:

Porque geralmente a produção, ela não... ela enxerga a necessidade da segurança, ela enxerga isso. Porém, como eles tão sempre com prazo apertado, eles tão sempre muito corridos, eles acabam não respeitando, não fazendo a coisa da forma que deveria ser feita (C.).

Porque é aquilo que falam, você acaba atrasando, porque a gente acaba atrasando o serviço do pessoal as vezes, né. Porque eles tem um tempo $\mathrm{X}$, e a gente precisa que primeiro se planeje, se adequa, depois começa. E com a produção é o contrário. Eles começam, pra depois a gente conseguir fazer, entendeu? (C.).

A preocupação com o dinheiro, que surge da organização do trabalho e se reproduz nos trabalhadores, fica evidenciada na seguinte fala: "Se eu não realizar aquela 
integração, se eu não autorizar aquela documentação antes do previsto, com certeza a empresa vai perder dinheiro por conta disso" (A.).

No entanto, é possível perceber na própria fala destes trabalhadores que eles mesmos também são capturados por esta lógica. Ao pensar em segurança, eles tendem a reproduzir que a segurança depende exclusivamente de cada trabalhador, e, consequentemente, o trabalho deles de cuidar da integridade física dos outros trabalhadores esta diretamente ligada a convencê-los a usarem equipamentos de segurança. Fala-se muito em "trazer os outros trabalhadores para o nosso lado". Esta questão está evidenciada nos seguintes trechos: "O nosso trabalho depende do pessoal da produção, que sem eles a gente não pode executar as atividades" (D.), "Assim, a gente não é responsável pela segurança direta do colaborador, cada um tem sua responsabilidade nisso" (D.) e "Até porque, de a gente conseguir trazer pessoas para o nosso lado, conscientizar desde o ajudante ao chefe, a gente conseguir mudar a mente deles, que dá para a gente melhorar a condição de um ambiente de trabalho (E.)".

Uma das técnicas de segurança que atuam na gestão do consórcio da obra de mobilidade urbana, foi a única a trazer que acredita que a falha não é do acidentado. Mas ao responsabilizar a organização do trabalho, ela culpabiliza o consórcio não pelas condições de trabalho que existem naquele contexto, mas pela contratação do trabalhador errado, e pela não substituição dele:

E eu costumo dizer, ainda mais, que geralmente a falha não é do acidentado. Dificilmente a falha é do acidentado. Porque pra ele ter se acidentado, ou foi mal contratado ou ele já vinha fazendo vários desvios, não atendendo vários procedimentos de segurança e identificou e não substituiu o funcionário. Então, para você ver que a culpa sempre vai ser do consórcio. (A.).

Embora tudo isso seja evidenciado, é possível perceber que eles entendem que a organização do trabalho não tem a segurança como a prioridade. Embora com certo receio e muito cuidado ao falar deste tema, a questão fica evidenciada na fala deles: 
[Em outra obra trabalhada anteriormente] a base da obra é a segurança a do trabalho. Nessa daqui não, essa daqui eles conciliam, faz uma conciliação, segurança qualidade e produção, entendeu? então acaba sendo os três interligados (F.).

\subsection{NÚCLEO 2: "NÃO É UM TRABALHO FÁCIL PORQUE LIDAR COM GENTE É UM POUCO PUXADO, UM POUCO DIFÍCIL."}

O núcleo "Não é um trabalho fácil porque lidar com gente é um pouco puxado, um pouco difícil." retrata as vivências de sofrimento no trabalho. Durante as entrevistas, todos os técnicos, principalmente os que trabalham diretamente no campo, trouxeram com muita ênfase a dificuldade que é lidar com os outros trabalhadores, tanto os que atuam na frente de serviço quanto os engenheiros, de quem recebem as orientações: "A dificuldade é que assim, é porque lidar com pessoas nunca é fácil, o temperamento, cada um tem um temperamento diferente, é.. tem" (D.).

Esta percepção de dificuldade é trazida relativizando-a ao temperamento dos outros trabalhadores. Os cargos também são trazidos frequentemente: "A gente tem bastante dificuldade em lidar com encarregados de vários temperamentos, a dificuldade maior é essa, é a questão do temperamento das pessoas" (D.) e "E tem Engenheiro também que o cara acha que é o cara. Entendeu? Aí vira para você "Oh, eu sou Engenheiro da obra e não vou fazer." (A.).

É possível ainda observar este aspecto na seguinte fala:

A gente tenta, particularmente a gente tenta saber a hora de agir né, saber a hora de falar algo, porque nem sempre as pessoas em serviço vai te receber bem, a gente tem que saber lidar com todos os tipos de pessoas, desde um ajudante a um engenheiro de produção, que a gente lida diretamente com eles (E.).

Novamente é possível perceber que os técnicos acabam por culpabilizar também o trabalhador da frente de serviço, muitas vezes acreditando que o não cumprimento 
das normas de segurança por parte deles está vinculado a falta de estudo, como é possível visualizar no trecho abaixo:

É, a dificuldade é essa, mais lidar com essa diversidade de público, né? As vezes eu pego um Peão, um Ajudante de Obra, aquele cara que só enxerga o que mandam, não tem aquele, ah, que não sabe diferenciar o que é certo do que é errado, entendeu? Então é complicado, às vezes o cara olha pra você e fala "Oh, não vou fazer isso.", vira as costas e vai embora (A.).

O sofrimento no trabalho também é evidenciado pela forma como a questão do estresse atravessa o discurso de todos os técnicos e como, por vezes, sentem-se vistos negativamente por outros trabalhadores: "Em relação ao estresse constante para cuidar da vida de adultos, né?" (C.) e "Apesar de a gente ser muita das vezes pra eles algum chato" (E.).

Outra forma de sofrimento vivenciada por eles é como o trabalho, por vezes, afeta negativamente o ambiente familiar destes trabalhadores: "Eu às vezes desconto isso um pouco nas pessoas fora do trabalho, entendeu? [...] Porque acabo descontando em mãe, pai, namorada, marido, mulher, seja lá o lado que for, entendeu?" (A.) e "O ponto negativo é eu estar bastante ausente na vida do meu filho. [...] Não consigo participar da educação, quem fica com ele é praticamente a minha mãe" (B.).

Há também outras vivências de sofrimento que emergiram nas entrevistas, porém de formas bastante sutis. Questionamentos a cerca da organização do trabalho foram trazidos pelos funcionários através de palavras selecionadas. Este aspecto foi entendido como uma cautela por parte destes trabalhadores, por terem medo de questionar abertamente o contexto de seus trabalhos. É possível perceber as voltas que os trabalhadores dão para trazer esta questão na fala abaixo:

Existe algumas concessões ou até mesmo procedimentos que são criados na própria empresa, que muda de empresa para empresa, então pra gente poder permanecer no mercado de trabalho, a primeira coisa 
que um técnico de segurança do trabalho tem que saber é se adaptar (F.).

Não vou falar de negligenciável não, é tipo assim, é fulano ocupa determinado cardo, a pessoa ocupa determinado cargo e essa pessoa todo mundo tem que se, tudo que vai fazer tem que chegar essa informação primeiro pra essa pessoa, e isso reflete também na questão da segurança, entendeu? (F.).

\subsection{NÚCLEO 3: "E EU COOPEREI PRA ISSO, É MUITO BOM.”}

O núcleo "E eu cooperei para isso, é muito bom." indica as vivências de prazer no trabalho. O prazer no trabalho, para estes trabalhadores, está ligado ao bem-estar que experienciam ao sentirem que ajudam a preservar a vida de outros trabalhadores:

Você sente a satisfação em saber que uma atitude sua promoveu um dia a mais na vida de alguém [...] Eu, quando descubro que algo que eu fiz, algo que a equipe fez junta, rendeu pra proteção, pro cuidado, pra alguém amanhã tá aqui na obra de novo... nossa, isso pra mim é maravilhoso! (C.).

Eu me sinto realizado, que é muito bom assim, a gente poder ajudar as pessoas na frente de serviço, a gente saber que aquele colaborador pode voltar pra casa com integridade física boa é devido a um pouco da minha cooperação na frente de serviço, é saber que quando ele for pra casa de ferias ou de folga de campo a família vai receber ele de braços abertos com integridade física boa e eu cooperei pra isso, é muito bom (D.).

As vivências de prazer também podem ser identificadas no reconhecimento do seu trabalho pelos outros trabalhadores:

Eu fiz primeiro atendimento num colaborador que teve um acidente na frente de serviço. Ai isso na primeira obra que eu trabalhei,. Quando eu 
cheguei na segunda obra, ele tava, ele tava na obra, me agradeceu bastante pelo que eu tinha feito com ele, encontrei com ele na rua e ele me apresentou a esposa e tal "olha, esse aqui é o segurança que me atendeu quando eu me acidentei e tal, em tal obra e a gente ter esse reconhecimento assim pelas pessoas é muito gratificante, muito bom" (D.).

\subsection{NÚCLEO 4: "ESSES SÃO OS PONTOS NEGATIVOS. MAS OS PONTOS POSITIVOS TAMBÉM ACABAM FAZENDO VALER."}

O núcleo "Esses são os pontos negativos. Mas os pontos positivos também acabam fazendo valer." expressa as estratégias defensivas empregadas por estes trabalhadores. Quando não é possível subverter o sofrimento no trabalho, o trabalhador busca minimizar a percepção deste sofrimento por meio de estratégias, que podem ser individuais, mas que funcionam melhor se forem coletivas. $O$ objetivo destas estratégias é permitir que o trabalhador continue trabalhando, mesmo frente as adversidades.

Em diversos momentos das entrevistas ocorridas com os técnicos que atuam nas duas obras, foi possível observar no discurso a resistência psíquica através da negação do sofrimento. Em diversas perguntas que procuravam investigar o sofrimento no trabalho, a resposta ligada ao sofrimento vinha sempre seguida de um aspecto positivo do trabalho. Falar um aspecto positivo era como o ponto final de toda frase que tratasse de dificuldades, como é possível observar nos seguintes trechos: "Esses são os pontos negativos. Mas os pontos positivos também acabam fazendo valer" (C.), "Aí vira pra você "Oh, eu sou engenheiro da obra e não vou fazer." Mas tem gente, pessoas muito boas" (A.), "Eu gosto do que faço, é bem estressante, isso é bom (A.)" e "Muitas das vezes querem trapacear a gente e querem fazer de qualquer forma, e a gente tem atritos e tal. Atritos em boa prática assim" (E.).

Observou-se, desta forma, que os técnicos não conseguiam se conectar com seu sofrimento. Foram formuladas duas hipóteses para esta questão. Uma delas considera que o medo da exposição, o medo de transparecer este sofrimento e estas 
questões chegarem aos seus superiores, mesmo que a pesquisa tenha procurado deixar bastante claro seu aspecto sigiloso. A outra hipótese seria que estas estratégias defensivas já estão tão bem estruturadas nestes trabalhadores que, mesmo entre si, já estão naturalizadas.

Quanto a outras estratégias defensivas coletivas, foi possível perceber nas entrevistas que, em meio as adversidades do trabalho, estes técnicos de segurança do trabalho buscam estabelecer relações próximas com os outros trabalhadores e aumentar a tolerância ao lidar com dificuldades na comunicação dentro do ambiente de trabalho. Estes aspectos podem ser observados nos seguintes trechos: "Querendo ou não, o técnico de segurança numa obra como essa ele é praticamente tudo, ele é psicólogo, ele tem que aprender a ouvir" (F.), "Eu busco meios de tentar me aproximar ao máximo desta pessoa para poder ganhar a confiança dela e ela entender que realmente o que eu quero é o bem de todos né" (F.) e "Então equilíbrio é tudo, e cooperação também. Só que você tem que buscar, achar uma forma de conquistar esse equilíbrio e a cooperação da galera" (E.).

Não foi perceptível em nenhuma das seis entrevistas aspectos que denunciassem algum nível de sofrimento patogênico ou adoecimento devido a essa relação com a organização do trabalho.

\subsection{NÚCLEO 5: "O TRABALHO AQUI REPERCUTE NA VIDA PESSOAL DA GENTE."}

O núcleo "O trabalho aqui repercute na vida pessoal da gente." busca compreender o sentido atribuído ao ato de trabalhar em sua atividade profissional.

Algumas falas apontaram a importância do trabalho como um aspecto que impulsiona o amadurecimento, através das diversas experiências de aprendizado:

Então, eu acho que cresci muito como homem. Porque eu sou um cara de vinte e quatro anos, comecei com dezoito em obra e sempre fui aquele cara que, tipo, tem um padrão de vida bom, sempre teve de tudo, 
os amigos sempre tiveram tudo. Eu acho que eu fui criando responsabilidade, entendeu?[...]. Eu acho que com vinte e quatro anos eu já amadureci muito. Mas também tenho muito que amadurecer, normal. Acho que é muito bom, o trabalho é bom, você aprende muita coisa. (A.).

Eu era 'largadão', na minha vida pessoal, agora não, minha mãe mesmo fala que eu mudei de mais, que agradece a Deus e a esse meu trabalho pelo fato de eu ter mudado tanto, hoje eu sou muito mais responsável, que assim, a gente, o trabalho aqui repercute na vida pessoal da gente (D.).

O trabalho também foi trazido como o que possibilita adquirir bens próprios fora do trabalho:

Desde aquela hora que você "Oh, teu primeiro salário é $X$. Tu vai ter ' $\mathrm{X}$ ' pra gastar e tu vai ter ' $x$ ' responsabilidades', entendeu? Ai tu vai aprendendo, tu começa a conquistar suas coisas. Começa a comprar seu primeiro carro, ai você começa a dar entrada no seu apartamento, ai você vai crescendo como homem. (A.).

Eu preciso do trabalho pra sustentar meu filho, eu preciso do trabalho pra pagar os meus estudos, pra crescer mais ainda. Eu preciso do trabalho pra me manter. Então, além da minha realização pessoal como profissional em Técnica de Segurança do Trabalho, eu também tenho a minha realização pessoal fora do trabalho. Que a gente precisa dele pra poder conquistar outras coisas externamente (A.).

A realização no trabalho também emergiu através de sentir-se útil em auxiliar no trabalho e na vida de outros:

Ai, é o que eu falo sempre. É cuidar de vidas. Então pra mim é muito importante. O ato que é... Você sente a satisfação em saber que uma atitude sua promoveu um dia a mais na vida de alguém. Então isso é 
muito bom pra mim, porque apesar de ser essa correria, de ser pessoas que não convivem, eu gosto muito de cuidar do ser humano. Eu quando descubro que algo que eu fiz, algo que a equipe fez junta, rendeu pra proteção, pro cuidado, pra alguém amanhã tá aqui na obra de novo... Nossa, isso pra mim é maravilhoso! Apesar de todo o desespero, de toda a correria. Mas faz bem pra caramba (C.).

Portanto, por mais que dentro de sua categoria profissional todos estes trabalhadores encontrem contextos diferentes e funções variadas, suas percepções convergem para uma apreciação e sentido que possuem representatividade coletiva. Há percepção de desenvolvimento e satisfação direta, ao trabalhar e sentir-se útil por isso, e indireta, ao usufruir fora do trabalho aquilo que este Ihes proporciona.

E, para além do sentido do trabalho como estimulador de autonomia e saúde, existem também os efeitos positivos e negativos que repercutem na vida de cada um.

Olha, na minha vida posso dizer que... me reeducou no sentido de controle. É como eu te falei, essa questão de buscar esse equilíbrio pra lidar com as pessoas. Antes eu era muito impulsiva. Tipo, eu recebia o desaforo e rebatia imediatamente. Hoje em dia, não. Hoje em dia eu já consigo receber o desaforo, respirar fundo, me controlar, tentar mostrar. Se eu perceber que não vou conseguir mostrar imediatamente, eu consigo me retirar (C.).

"O meu temperamento é muito forte, e com meu envolvimento nessa área eu aprendi muito a superar meu próprio temperamento e eu agora sou mais cabeça" (D.).

Nesta duas falas destacadas, por exemplo, os trabalhadores apontam uma reeducação de seu comportamento para conseguir lidar com as demandas de seu trabalho, e hoje se percebem menos impulsivos e mais equilibrados em sua vida.

Através destes cinco núcleos de sentido, portanto, foi possível analisar algumas questões do universo do trabalho dos técnicos de segurança do trabalho sob a ótica da psicodinâmica do trabalho. 


\section{CONSIDERAÇÕES FINAIS}

A configuração dos tempos atuais, que tem como marco de início a Revolução Industrial, revela uma perspectiva de trabalho onde imperam o produtivismo e a competitividade, em detrimento dos valores éticos. Desta forma, a vida fica em segundo plano, e qualquer movimento contrário ao que dita este modelo pode representar a exclusão e o isolamento daquele que se manifesta.

Desta forma, para manter-se parte deste cruel mundo do trabalho, os sujeitos utilizamse inconscientemente de estratégias defensivas. Na tentativa de diminuir a percepção do próprio sofrimento, desencadeiam-se comportamentos que aumentam o individualismo e neutralizam a mobilização subjetiva. É preciso não ver, não ouvir e não falar, tornar-se insensível para poder seguir trabalhando (FERREIRA, 2009).

Para a saúde mental, são inúmeros os prejuízos. O individualismo exacerbado desestrutura a solidariedade, e vivências patológicas como a depressão, o estresse, a angústia, passam a ser cada vez mais comuns dentre os trabalhadores. No meio deste sofrimento sufocado, perde-se o sentido no trabalho, o que pode resultar, no limite, na perda de identidade do sujeito (FERREIRA, 2009).

Nesta linha, há também grandes prejuízos no que tange à saúde e segurança dos trabalhadores. No contexto do trabalho na contemporaneidade, as novas formas de gestão sutilmente impõem suas condições. Se os valores são o do produtivismo acima de tudo, estar doente para um trabalhador pode significar a exclusão, o descarte, uma vez que sua capacidade produtiva está comprometida (MENDES \& WÜNSCH, 2007).

Indo mais além, a prevenção da saúde do trabalhador está centrada no próprio indivíduo. A segurança deve ser praticada por, e é responsabilidade individual de cada trabalhador. Esta visão oculta que é o próprio contexto da organização do trabalho, com sua lógica, o responsável pelo altos números de acidentes de trabalho. Desconsiderando as suas condições de vida, o resultado, portanto, é a culpabilização do próprio trabalhador (MENDES \& WÜNSCH, 2007). 
Estes pontos foram observados nas entrevistas realizadas com os técnicos de segurança. Foi trazido por eles, em diversos momentos, que em uma obra, a única regra inviolável é que a produção não pode parar. A segurança do trabalho, por vezes, é vista como a área que atrasa a produção. Desta forma, são muitas as situações em que a segurança é deixada de lado em prol do tempo da produção.

Nos discursos trazidos nas entrevistas, foi possível perceber também que os próprios técnicos acabam capturados por esta lógica, quando acreditam que a responsabilidade pela segurança está exclusivamente em cada trabalhador. Apenas uma das técnicas expressou não acreditar que a culpa seja do acidentado, porém, em sua justificativa, a culpa é da organização pela má contratação ou não substituição do trabalhador. Ligada à culpabilização do trabalhador que está na frente de serviço, são trazidas vivências de sofrimento no que concerne a interação com outros trabalhadores, pautando a justificativa, em determinados momentos, na falta de estudo dos trabalhadores.

$\mathrm{Na}$ análise psicodinâmica do trabalho destes técnicos de segurança, foi visto também que vivências de prazer no trabalho estão ligadas ao bem-estar que experienciam ao sentirem que ajudam a preservar a vida de outros trabalhadores, e no reconhecimento do seu trabalho pelos outros trabalhadores.

Sobre as estratégias defensivas, estes trabalhadores buscam minimizar a percepção de seu sofrimento por meio da negação do sofrimento. Em diversas perguntas que procuravam investigar o sofrimento no trabalho, a resposta ligada ao sofrimento era seguida sempre de um aspecto positivo do trabalho. Falar um aspecto positivo era como o ponto final de toda frase que tratasse de dificuldades. Outra estratégia defensiva percebida foi que, em meio as adversidades do trabalho, estes técnicos de segurança buscam estabelecer relações próximas com os outros trabalhadores e aumentar a tolerância ao lidar com dificuldades na comunicação dentro do ambiente de trabalho.

Embora tenha-se identificado estas estratégias defensivas, não houve na entrevista de nenhum dos seis técnicos, indícios que levassem a perceber algum nível de 
sofrimento patogênico ou adoecimento em suas relações com a organização do trabalho em que estão inseridos.

Quanto ao último núcleo de sentido identificado, que diz respeito ao sentido do trabalho, foi possível perceber que, para eles, o trabalho impulsiona o amadurecimento, através das diversas experiências de aprendizado, possibilita a independência financeira, além de sentir-se útil em auxiliar no trabalho e na vida de outros.

A partir das análises das entrevistas, conclui-se que há um longo caminho a ser percorrido para que a saúde e a segurança dos trabalhadores se desvincule da lógica da produção. Para que, de fato a integridade dos trabalhadores seja preservada, a segurança deve deixar de pregar a culpabilização do trabalhador e ser debatida a partir das condições e relações de trabalho, repensando-se a própria organização do trabalho.

Este trabalho traz como sugestão o uso da clínica psicodinâmica da cooperação como instrumento capaz de possibilitar mudanças na organização do trabalho. Privilegiando-se a fala coletiva, será possível evidenciar as características próprias de cada contexto de trabalho, abrindo espaço para a mobilização subjetiva deste coletivo em busca de melhores condições.

\section{REFERÊNCIAS}

ANTLOGA, Carla Sabrina. Segurança no Trabalho. In: VIEIRA, Fernando de Oliveira; MENDES, Ana Magnólia; MERLO, Álvaro Roberto Crespo (orgs.). Dicionário Crítico de Gestão e Psicodinâmica do Trabalho. 1를 edição. Curitiba: Juruá, 2013. pp.369374.

BRASIL, Ministério do Trabalho e Emprego. CBO - Classificação Brasileira de Ocupações, 2002. Disponível em: <http://www.mtecbo.gov.br/cbosite/pages/home.jsf>. Acesso em: 25/09/2014. 
BRASIL, Ministério do Trabalho e Emprego. FUNDACENTRO. Missão da FUNDACENTRO. Disponível em: <http://www.fundacentro.gov.br/institucional/inicio> Acesso em: 25/09/2014.

BRASIL. Ministério do Trabalho e Emprego. Lei no 6.514, de 22 de dezembro de 1977. Altera o Capítulo $V$ do Título II da Consolidação das Leis do Trabalho relativo à segurança e medicina do trabalho e dá outras providências. Brasília, 1977. Disponível em: <http://www.planalto.gov.br/ccivil_03/leis/l6514.htm>. Acesso em: 27/09/2014

BRASIL, Ministério do Trabalho e Emprego. NR 04 - Serviços Especializados em Engenharia de Segurança e em Medicina do Trabalho. Brasília, 1983. Disponível em: <http://www3.dataprev.gov.br/sislex/paginas/05/mtb/4.htm>. Acesso em: 25/09/2014

COSTA, Sérgio Henrique Barroca. Trabalho Prescrito e Trabalho Real. In: VIEIRA, Fernando de Oliveira; MENDES, Ana Magnólia; MERLO, Álvaro Roberto Crespo (orgs.). Dicionário Crítico de Gestão e Psicodinâmica do Trabalho. 1a edição. Curitiba: Juruá, 2013. pp.467-472.

DECCA, Edgar Salvadori de. O Nascimento das Fábricas. 10ª edição. São Paulo: Brasiliense, 1995.

DEJOURS, Christophe. A Banalização da Injustiça Social. $7^{a}$ edição. Rio de Janeiro: Fundação Getúlio Vargas Editora, 1999.

DEJOURS, Christophe. Addendum, da psicopatologia à psicodinâmica do trabalho, In: LANCMAN, Selma.; SZNELWAR, Laerte Idal (orgs.). Christophe Dejours: da psicopatologia à psicodinâmica do trabalho. 3aㅗ edição. Brasília: Paralelo 15; Rio de Janeiro: Editora Fiocruz, 2011. pp.57-123.

FERREIRA, João Batista. Perdi um jeito de sorrir que eu tinha: violência, assédio moral e servidão voluntária no trabalho. 1a edição. Rio de Janeiro: 7Letras, 2009. 
MENDES, Ana Magnólia. Pesquisa em psicodinâmica: a clínica do trabalho. In: MENDES, Ana Magnólia (org.). Psicodinâmica do trabalho: teoria, método e pesquisa. 1ª edição. São Paulo: Casa do Psicólogo, 2007.

MENDES, Ana Magnólia; DUARTE, Fernanda Sousa. Mobilização Subjetiva. In: VIEIRA, Fernando de Oliveira; MENDES, Ana Magnólia; MERLO, Álvaro Roberto Crespo (orgs.). Dicionário Crítico de Gestão e Psicodinâmica do Trabalho. $1^{\text {a }}$ edição. Curitiba: Juruá, 2013. pp.259-262.

MENDES, Ana Magnólia; MULLER, Thiele da Costa. Prazer no Trabalho. In: VIEIRA, Fernando de Oliveira; MENDES, Ana Magnólia; MERLO, Álvaro Roberto Crespo (orgs.). Dicionário Crítico de Gestão e Psicodinâmica do Trabalho. 1ª edição. Curitiba: Juruá, 2013. pp.289-292.

MENDES, Jussara Maria Rosa; WÜNSCH, Dolores Sanches. Elementos para uma nova cultura em segurança e saúde no trabalho. Revista Brasileira de Saúde Ocupacional, São Paulo, vol.32, n.115, pp.153-163, 2007. ISSN 0303-7657. Disponível em: <https://doi.org/10.1590/S0303-76572007000100014>. Acesso em: 20/09/2014.

MENDES, René; DIAS, Elizabeth Costa. Da medicina do trabalho à saúde do trabalhador. Revista de Saúde Pública, São Paulo, vol.25, n.5, pp.341-349, 1991. ISSN 0034-8910. Disponível em: <https://doi.org/10.1590/S00389101991000500003>. Acesso em: 20/09/2014.

MINAYO, Maria Cecília de Souza (org.). Pesquisa Social. Teoria, método e criatividade. 33a edição. Petrópolis: Vozes, 2013.

MORAES, Rosângela Dutra de. Estratégias Defensivas. In: VIEIRA, Fernando de Oliveira; MENDES, Ana Magnólia; MERLO, Álvaro Roberto Crespo (orgs.). Dicionário Crítico de Gestão e Psicodinâmica do Trabalho. 1르 edição. Curitiba: Juruá, 2013. pp.153-158. 
VASCONCELOS, Mônica. BBC, 2014. Acidentes nos estádios da Copa: crônicas de nove mortes anunciadas? Disponível em: $<$ http://www.bbc.co.uk/portuguese/noticias/2014/08/140811_mortes_estadios_copa_ mv>. Acesso em: 19/09/2014

Enviado: Abril, 2020.

Aprovado: Abril, 2020. 